\title{
Laboratório do controle e controle do laboratório: práticas e táticas do poder e o problema da servidão voluntária
}

\author{
Laboratory of the control and control of the laboratory: practices and tactics of \\ power and the problem of the voluntary servitude
}

\author{
Elcemir Paço-Cunha ${ }^{1}$ \\ Flávia Aparecida Gomes ${ }^{2}$ \\ Renata de Almeida Bicalho ${ }^{3}$
}

Resumo

O objetivo deste artigo é desvendar os mecanismos de controle e as táticas desenvolvidas em face desses mecanismos, no espaço de um laboratório de análise de alimentos e águas onde encontramos professores e alunos vinculados a uma faculdade de farmácia de uma universidade pública no estado de Minas Gerais. Utilizou-se, de um lado, as idéias de Foucault sobre o poder disciplinar nas organizações e, de outro, as idéias de Certeau sobre as táticas que permitem questionar a eficácia do poder disciplinar. Para tanto, empreendeuse uma pesquisa de cunho qualitativo, por meio de entrevistas, do levantamento de dados secundários e da observação não-participante. Os resultados da pesquisa denotam mecanismos de controle sobre as atividades de trabalho - como as regras de conduta e de operação de equipamentos sofisticados, o controle dos horários e do vestuário - $e$, ainda, a indicação de alguns alunos para esse exercício. Os resultados também indicam a existência de táticas que driblam tais mecanismos na execução do trabalho diário. $O$ artigo também discute um paradoxo identificado durante a investigação, que é a vontade manifestada pelos produtores das táticas de que haja um maior controle sobre eles próprios. $O$ artigo questiona os referenciais teóricos que fundamentaram sua própria elaboração e propõe um debate sobre a idéia de servidão voluntária de La Boétie.

Palavras-chave: controle; poder; práticas e táticas do poder.

\section{Abstract}

The objective of this article is to expose the mechanisms of control and the developed tactics front it in the laboratory of analysis of foods and waters, associated to a pharmacy college of a public university in the state of Minas Gerais. It was used the ideas of Foucault on discipline power and the ideas of Certeau on tactics. The methodology resources were interviews, secondary data and observation. The results of the research denotes the control mechanisms on the activities of work, as the rules of behavior and sophisticated equipment operation, control of the schedules and clothes and, still, indication of some pupils for this exercise. The results also indicate the existence of tactics that dribble such mechanisms in the execution of the daily work. The article also presents a discussion on the paradox identified during the inquiry in which the producers of the

\footnotetext{
1 Mestre em Administração - Universidade Federal de Lavras - UFLA.Doutorando do Centro de Pós-graduação e Pesquisas em Administração na Universidade Federal de Minas Gerais-UFMG. Professor do Departamento de Ciências Administrativas - Universidade Federal de Juiz de Fora-UFJF. Endereço: Rua Icaraí, 469 - apt. 202 - Bairro Caiçara - Belo Horizonte/Minas Gerais - Brasil. CEP: 30770-160. E-mail:paco.cunha@ufjf.edu.br

${ }^{2}$ Graduada em Administração pela Universidade Federal de Juiz de Fora- UFJF. Pesquisadora independente.Endereço: Rua Santo Antônio, 1465 , apto 215 - Centro - Juiz de Fora/Minas Gerais - Brasil - CEP: 36016210. E-mail: gomesflaviagomesufjf@yahoo.com.br.

${ }^{3}$ Graduada em Administração pela Universidade Federal de Juiz de Fora- - UFJF Mestranda do Centro de Pós-graduação e Pesquisas em Administração na Universidade Federal de Minas Gerais-UFMG.Endereço Endereço: Rua Icaraí, 469 - apt. 202 - Bairro Caiçara - Belo Horizonte/Minas Gerais - Brasil. CEP: 30770-160.. E-mail: rabicalho@yahoo.com.br

Artigo submetido em março e aceito em julho de 2008
} 
tactics desire more control directed at their own persons. A questioning of the theoretical bases that were used initially for the elaboration of the article is presented and a proposal of a debate on the idea of voluntary servitude of La Boétie is made.

Key words: control; power; practices and tactics of power.

\section{Introdução}

O controle é um tema que desperta interesse no âmbito acadêmico, não apenas nos estudos organizacionais, mas também na filosofia e nas ciências humanas. O tema é freqüentemente associado à questão do poder e da ordenação social, de forma que as práticas de controle, num amplo sentido, representam o exercício do poder na manutenção de determinado status quo. Não por acaso, é emblemática a assertiva platônica de que a polis se organizava entre políticos, militares, cidadãos comuns e escravos, de sorte que qualquer alteração provocaria a destruição daquela sociedade. Numa linha semelhante, Hobbes (1974) acreditava que o homem necessita estar submetido a um poder centralizador e coercitivo que garanta o progresso ordenado e contínuo, pois do contrário, teríamos uma guerra de todos contra todos. ${ }^{1}$ Não por acaso, também em Comte aparece uma sociologia comprometida com a harmonia industrial, rejeitando qualquer forma de revolução contra a ordem social estabelecida (MARCUSE, 1969).

Esse caráter regulativo do controle social toma, mais tarde, nas mãos de Parsons (1960), ares de integração numa expressão muito clara das idéias de Durkheim (2004) quanto às forças sociais - e nem tanto nas de Weber $(1999,2002)$, sobre a capacidade ordenadora da forma organizacional burocrática. Essa integração foi cara a Barnard (1971) e a Simon (MARCH; SIMON, 1970). Da mesma forma ainda o é para os estudos gerenciais, que utilizam tantos outros termos para designar a mesma coisa, como, por exemplo, equilíbrio, homeostase, compartilhamento de valores, coerência interna e externa, funcional (e disfuncional ou desviante) etc. A idéia de integração não pretende outra coisa senão a ordenação social, em seu aspecto amplo e situado na forma de organizações e instituições.

Muitos estudiosos não tardaram a combater tais idéias. Nos estudos críticos, o poder e o controle representam o cerne das reflexões. Há uma forma diferente de engajamento nas idéias e no mundo empírico; pelo menos, no âmbito da tradição hobbesiana e dos seus herdeiros nos estudos organizacionais, incluindo aí os funcionalistas e a ciência positiva, esta última no sentido de Marcuse (1969). Diferentemente dos que estão preocupados com "o que fazer para as organizações darem certo", os críticos apontam "o que elas fazem para tal". Para estes, aquelas proposições - e tudo relacionado à implantação daquela ordem organizacional, do legítimo e do ilegítimo, do funcional e do disfuncional - tornam-se, senão, descabidas, ao menos, infundadas. Existem, para os críticos, relações de dominação expressas na ordem tida e proposta como legítima.

O desenvolvimento dessa linha de raciocínio se encontra, por um lado, nas interpretações de Marx (1987) sobre os trabalhos de Hegel (2000), pois, conforme argumenta Cassirer (2003, p.303), “[...] Hegel não procura a 'Idéia' em qualquer espaço supercelestial. Encontra-se na atualidade da vida social do homem e das lutas políticas".

Movido por um espírito inquieto e combativo, ao apontar interesses e lógicas, Marx expôs uma posição denunciativa ante o mundo, cuja tônica é o capitalismo (GIDDENS, 1991). Essa postura também é percebida na idéia weberiana de racionalização do mundo e de que, quanto mais for desenvolvida a forma burocrática de organização, menor será a espiritualidade humana.

Talvez aqui se estabeleça uma questão-chave na inspiração crítica, não necessariamente apenas marxista, guardadas as devidas variações: a forma de engajamento adotada leva ao reconhecimento e à denúncia de que o 
poder está centralizado nas mãos de poucos, gerando todo tipo de desigualdade (social e organizacional). Nesse sentido, tal centralização deveria ser superada para que se estabelecesse uma nova ordem, a do proletariado (no sentido do marxismo ortodoxo), uma ordem sem distorções nem repressões (no sentido de Habermas FREITAG; ROUANET [2001]); uma ordem de (micro) emancipação humana (ALVESSOM; WILLMOTT, 1992). Como indica Gaulejac (2006) e seus amigos francofônicos, em adição, seria uma ordem que respeitasse o desejo natural do sujeito de ser tratado como tal, sem violência, nem sofrimento patológico.

Argumentamos neste artigo que essa polarização de idéias não abarca a complexidade do tema com o qual se pretende lidar, o que não significa que pleiteemos uma terceira via ou o término definitivo dos dualismos. ${ }^{2} \mathrm{Se}$ por um lado o controle não pode ser totalmente garantido, por outro, os sujeitos desenvolvem vários tipos de relações com as formas de controle, muitas vezes, controlando-as. Para elucidar teoricamente nossa posição, optamos por retomar não apenas as idéias de Foucault, visando elucidar o exercício do poder e como este se manifesta através dos mecanismos de controle, mas também as de Certeau. Nosso intuito foi indicar os movimentos infinitesimais, isto é, as táticas, que, para Certeau, não teriam sido consideradas por Foucault. Assim, procuramos levantar uma discussão teórica que elucide as práticas do poder, expressas pelos mecanismos de controle, e as táticas do poder, expressas nos malabarismos ante tais mecanismos.

Nosso projeto inicial foi desvendar os mecanismos de controle e as táticas desenvolvidas em face desses mecanismos, no espaço de um laboratório de análise de alimentos e águas, onde encontramos professores e alunos vinculados a uma faculdade de farmácia de uma universidade pública no estado de Minas Gerais. Esse tipo de abordagem já foi realizado por Paço-Cunha et al (2006) em uma empresa de call center. Entretanto, no transcorrer da investigação nos deparamos com um tipo de fenômeno estranho às idéias desses autores que operacionalizávamos. Diante disso, ao invés de simplesmente negarmos, preferimos indicar essa questão nas seções do artigo dedicadas à apresentação e à discussão dos resultados.

O artigo está estruturado em quatro seções, além desta introdução e das considerações finais. Na primeira seção, "Praticas e táticas do poder", abordamos as idéias de Foucault sobre, principalmente, o poder disciplinar e como este se expressa nas organizações por meio das formas de controle. Ainda nesta seção, contrapomos tais idéias às proposições de Certeau sobre as táticas desenvolvidas através de práticas ordinárias, as quais nos permitem questionar a idéia de corpo docilizado, ao mesmo tempo em que ilustram a ineficácia do poder disciplinar. Tais proposições evidenciam a fragilidade de alguns estudos publicados no Brasil que insistem na onipresença operatória e eficaz de tal poder disciplinar. Na segunda seção, expomos a metodologia seguida no acesso ao campo. Na seção seguinte, "Apresentação dos resultados", abrimos espaço para a discussão teóricoempírica, com o objetivo de refletir não apenas sobre a riqueza que nosso background permitiu, mas, principalmente, sobre nossa perplexidade ante um fenômeno inesperado, que é o desejo que os determinados indivíduos têm de serem mais controlados. Nesse momento, permitimo-nos, apresentar autores que não figuraram na nossa discussão teórica. Seguem-se, então, as considerações finais.

\section{Práticas e táticas do poder}

Nesta seção iremos explicitar as duas questões teóricas que norteiam o nosso background teórico. De um lado, as idéias de Foucault que evidenciam o exercício do poder disciplinar no interior das organizações e que, nesse sentido, representam as práticas do poder. De outro, as idéias de Certeau sobre as táticas (do poder), as quais trazem para a agenda de pesquisa o cotidiano organizacional e a astúcia humana no transcorrer do trabalho diário. Essa investida teórica é interessante, principalmente, porque, a grosso modo, os trabalhos desenvolvidos nos estudos organizacionais brasileiros enfatizam a eficácia do poder disciplinar (e.g. CAPPELLE; BRITO, 2003) em detrimento das trampolinagens dos indivíduos que atuam nas organizações. Essa discussão será útil 
para apreendermos a miríade de atividades desenvolvidas nas organizações, as quais estão aquém e além daquelas consideradas relevantes e que são tradicionalmente alvos de investigações à revelia do ordinário.

Foucault tem sido um autor bastante influente nos estudos organizacionais, especialmente, na discussão sobre o poder e o controle nas organizações. Thomas e Davies (2005) chamam de "foucaultian turn" o que Rosa (2006) denomina "efeito Foucault" nos estudos organizacionais.

Na visão de Foucault (1996, p.141),

de uma maneira geral, os mecanismos de poder nunca foram muito estudados na história. Estudaramse as pessoas que detiveram o poder. Era a história anedótica dos reis, dos generais. Ao que se opôs a história dos processos, das infra-estruturas econômicas.

O autor afirma que o importante não é definir o conceito de poder, mas, sim, as relações de poder e seus mecanismos utilizados, uma vez que o poder é algo abstrato e está em toda parte; não porque o poder engloba tudo ou porque está em todos os lugares, mas porque vem de todos os lados. A rede de relações de poder forma um tecido espesso que atravessa os aparelhos e as instituições, como algo que circula e só funciona em cadeia. $\mathrm{O}$ discurso, os saberes e as práticas constituiriam alguns dos mecanismos dessas relações, visando a uma série de objetivos.

Foucault (1988) relaciona a origem da moderna repressão sexual a uma forma de exercício de poder pela ordem burguesa, em consequiência da incompatibilidade entre sexualidade, exploração da força de trabalho e modos de produção. Para que as relações capitalistas gerem lucro, seria necessário estabelecer uma trama de poder microscópico (o subpoder) capaz de consolidar o vínculo entre os homens e o aparelho de produção, transformando os indivíduos em trabalhadores e participantes de um processo de fabricação de mercadorias e de geração de valor excedente. Assim, a organização do trabalho envolveria o sobrelucro e o subpoder.

No fim do século XVIII e começo do XIX, o suplício e a festa da punição e exposição do condenado foram se extinguindo. Surgia, então, outra modalidade de poder: "o poder disciplinar [que] tem por correlato uma individualidade não só analítica e celular, mas também natural e orgânica" (FOUCAULT, 1996). A disciplina seria uma técnica ou um conjunto de instrumentos que fabricam indivíduos úteis. Ela é capaz de aumentar a produtividade dos operários nas fábricas, a produção de saber, as aptidões nas escolas, a saúde nos hospitais e a força no Exército. Isso ocorre devido à multiplicação, na sociedade, de instituições de disciplina, como as fábricas, as prisões e as escolas (e, por que não dizer, as de administração). O poder converte-se em algo invisível, e para que o dispositivo disciplinar do olhar hierárquico fosse exercido plenamente, bastaria que aqueles que se encontram submetidos a ele saibam que são vigiados. A vigilância faz com que os indivíduos disciplinem-se a si mesmos, adestrem-se e se corrijam. A idéia maior é adestrar os indivíduos, tornando-os mais úteis, a partir do momento em que adquiram maiores habilidades e desenvolvam aptidões, gerando lucro. Essa forma de poder estaria, assim, materializada nos corpos dos indivíduos por ele criados.

O corpo humano entra numa maquinaria de poder que o esquadrinha, o desarticula e o recompõe. Uma "anatomia política", que é também igualmente uma "mecânica do poder", está nascendo; ela define como se pode ter domínio sobre o corpo dos outros, não simplesmente para que façam o que se quer, mas para que operem como se quer, com as técnicas, segundo a rapidez e a eficácia que se determina. A disciplina fabrica assim corpos submissos e exercitados, corpos "dóceis". (FOUCAULT, 2004, p.119)

Em termos de práticas explícitas, Foucault fornece um indicativo da técnica associada ao exercício do poder. As formas de "exame" - no início, no meio e no fim -, as distribuições espaciais, o controle da atividade, a vigilância e a sanção buscam o melhor enquadramento útil e obediente do fazer nesses espaços. 
Todavia, sumariamente, para Foucault (1988),

o poder vem de baixo; isto é, não há, no princípio das relações de poder, e como matriz geral, uma oposição binária e global entre os dominadores e os dominados, dualidade que repercuta de alto a baixo e sobre grupos cada vez mais restritos até as profundezas do corpo social. (Ibidem, p.90)

As relações de forças são demarcadas por alianças que se formam e que se dissolvem sem a necessária concentração de poder, pois, se um discurso constrói, outros solapam, na medida em que

onde há poder, há resistência e, no entanto (ou melhor, por isso mesmo), esta nunca se encontra em posição de exterioridade em relação ao poder. [...] Elas [as correlações de poder] podem existir senão em função de uma multiplicidade de pontos de resistência que representam, nas relações de poder, o papel de adversário, de alvo, de apoio, de saliência que permite apreensão. Esses pontos de resistência [sempre no plural] estão presentes em toda a rede de poder. (Ibidem, p.91)

Essas questões são interessantes e podem ser úteis para uma análise dos processos de trabalho numa organização. Se por um lado os mecanismos de vigilância, as regras e as sanções visam docilizar e adestrar os corpos, por outro, as relações de poder podem ser erigidas por meio da formação de alianças determinadas, as quais podem formar pontos de resistência.

Apesar de fecundas, as idéias de Foucault parecem ter como alvo aquelas práticas e procedimentos que "falam", que são aparentes e relevantes. Segundo Certeau (1994), o tratamento dado por Foucault não envolve "o estatuto de muitas outras séries que, prosseguindo em seus silenciosos itinerários, não deram lugar a uma configuração discursiva nem a uma sistematização tecnológica" (Ibidem, p.114). Em outros termos, tanto em Foucault como nos estudos organizacionais, de maneira geral, privilegiam-se as práticas relevantes em detrimento das ordinárias, as quais formam a miríade de atividades desenroladas no dia-a-dia das organizações. Em sua crítica às idéias foucaultianas, Certeau argumenta que:

A formação final (a tecnologia observadora e disciplinar contemporânea), que serve de ponto de partida para a história regressiva praticada por Foucault, explica a impressionante coerência das práticas que ele seleciona e examina. Mas será que se pode supor que o conjunto dos procedimentos tenha a mesma coerência? A priori, não. O desenvolvimento excepcional, até mesmo canceroso, dos procedimentos panópticos parece indissociável do papel histórico que lhes foi atribuído, o de ser uma arma para combater práticas heterogêneas e para controlá-las. A coerência é o efeito de um sucesso particular, e não a característica de todas as práticas tecnológicas. Sob o monoteísmo aparente a que se poderia comparar o privilégio que garantiram para si mesmos os dispositivos panópticos, sobreviveria um "politeísmo" de práticas disseminadas, dominadas, mas não apagadas pela carreira triunfal de uma entre elas. (Idem, 1994, p.115, grifos no original)

A pesquisa de Certeau (1994) se desenvolve pelo questionamento das operações dos usuários, supostamente, entregues à passividade e à disciplina. Segundo o autor, o cotidiano é capaz de ser reinventado de mil maneiras de "caça não autorizada". Isso porque o controle nunca pode ser totalmente assegurado ou garantido, pois o corpo humano não pode ser totalmente docilizado (PAÇO-CUNHA et al, 2006).

Muitas práticas cotidianas - como ler, falar, fazer compras ou preparar as refeições - são vistas por Certeau (1994) como um tipo de tática. As maneiras de fazer, que são as vitórias do mais fraco sobre o mais forte (os poderosos, a doença, a violência, a ordem), seriam performances operacionais resgatadas de saberes muito antigos. Certeau (1994, p.79) define sabedoria como as trampolinagens e trapaçarias, ou seja, as astúcias e espertezas presentes na maneira como se driblam os termos dos contratos sociais, as manipulações internas a um sistema. Para ele, 
tática [é] a ação calculada que é determinada pela ausência de um próprio. [...] A tática não tem lugar, senão o do outro. E por isso deve jogar com o terreno que lhe é imposto, tal como o organiza a lei de uma força estranha [...]: a tática é movimento "dentro do campo do inimigo" [...]. (Ibidem, p.100, grifos no original)

Em outros termos, as táticas podem ser vistas como um jogar com as práticas do poder disciplinar. Elas permitem questionar, portanto, a eficácia das práticas disciplinares, pois estão sempre à mercê da astúcia humana, das trampolinagens, das manobras. As táticas são a garantia de que existe vida no "meio" das disciplinas.

Com efeito, as táticas podem ser vistas como "pequenas liberdades" no interior das organizações e estão ligadas às atividades do dia-a-dia do trabalho. Permitem o questionamento sobre a real eficácia do poder disciplinar sobre os corpos. Resta-nos levar a cabo essa discussão para uma análise das atividades de trabalho numa dada organização.

\section{Metodologia}

Investigamos as práticas e as táticas do poder num laboratório de análise de alimentos e águas que reúne dois professores e cerca de 20 alunos, vinculados à faculdade de farmácia de uma universidade pública no estado de Minas Gerais. Trata-se de uma organização de natureza não-econômica, ligada a um projeto que une orientação à prática do profissional farmacêutico à prestação de serviços para a comunidade local. Os alunos desenvolvem atividades que requerem elevado grau de precisão e competência técnica, sendo orientados pelos professores, pois o manuseio dos objetos em análise exige extremo cuidado - para evitar contaminação das amostras - e a utilização de instrumentos de alta tecnologia.

Nossa discussão teórica já indica que dificilmente poderíamos acessar a realidade da organização pesquisada recorrendo a formas "estruturadas". Desse modo, adotamos uma abordagem qualitativa (BOGDAN; BIKLEN, 1994) da realidade ora investigada, que nos permitisse acessar tanto os aspectos mais ordinários quanto os não ditos desenrolados na organização. Concentramo-nos nas atividades desenvolvidas pelos alunos durante o fazer diário, sem abordarmos atividades administrativas ou decisões gerais. Nossa atenção foi dirigida para o processo de trabalho; isto é, para o modo como o trabalho é executado, no sentido atribuído por Braverman (1974).

Como expressão dessa abordagem qualitativa, o nosso acesso ao campo se deu de três formas distintas. Inicialmente, pela observação não-participante (HAGUETE, 2003; SILVERMAN, 1993) por parte de um dos autores deste artigo. O pesquisador acompanhou diariamente as atividades realizadas na empresa, desempenhando tarefas administrativas, todos os dias da semana, em contato direto com os alunos durante suas atividades, ainda que pesquisador e alunos desempenhassem tarefas diversas. Essa observação durou quatro meses (entre setembro de 2006 e janeiro de 2007), gerou notas de campo e permitiu uma maior aproximação com o cotidiano das pessoas no laboratório. Simultaneamente às observações, foram feitas análises dos documentos produzidos pela organização, as quais foram incorporadas às notas de campo. Em seguida, realizamos entrevistas não-estruturadas que, gravadas, foram posteriormente transcritas. Ouvimos dois professores (aqui identificados como Po1 e Po2), seis alunos bolsistas (Eb1, Eb2, Eb3, Eb4, Eb5 e Eb6) e seis alunos voluntários (Ev1, Ev2, Ev3, Ev4, Ev5 e Ev6). A combinação dessas técnicas visou evitar que se caísse na tendenciosidade que poderia advir da utilização de apenas uma delas, conforme sugerido por Denzin (1989).

Durante a coleta dos dados, ocorreram discussões entre os pesquisadores sobre qual direção os dados então obtidos estavam apontando. Nessas discussões, realizamos "leituras" exaustivas dos documentos fornecidos pela organização, das entrevistas transcritas e das notas de campo. Fizemos constantes comparações entre essas 
três fontes de dados para tentar apreender, em pormenores, o desenrolar do dia-a-dia organizacional. Nesse momento, percebemos outras questões, as quais, inicialmente, transcendiam (ou estavam aquém) do nosso background teórico. Ao invés de simplesmente ignorarmos o que os dados estavam indicando, demos ainda mais atenção. Essa atenção, conforme iremos apresentar mais adiante, levou-nos a questionar o próprio esquema teórico que tínhamos em mãos, o que expressava uma metodologia reflexiva.

\section{Apresentação dos resultados}

\section{Laboratório do controle: as práticas do poder}

Através dos relatos, das observações e da análise dos documentos foram identificadas algumas práticas de controle (discursivas e materiais) que operam na organização. De modo geral, tais práticas incidem sobre as atividades de: (a) padronização dos processos, (b) atendimento às normas de segurança, (c) prestação de serviço aos clientes, (d) frequiência dos estagiários e (e) distribuição de atividades e bolsas.

(a) Com relação à padronização dos processos, foi elaborado um documento com mais de 300 páginas, intitulado Manual de procedimentos operacionais padrão. Nele é informado como proceder durante a realização de todas as atividades ligadas ao trabalho diário e o manuseio dos equipamentos, desde como ligar e desligar um aparelho até como realizar a análise de um microorganismo "contaminante" em um produto acabado. Tais procedimentos são denominados pelos membros da organização de POPs (procedimentos operacionais padrão) e especificam todos os pequenos detalhes a serem levados em conta quando da execução das atividades pelos alunos.

A partir dos relatos dos professores, percebeu-se que a leitura dos POPs é quase obrigatória, pois adotar tais procedimentos assegura uma padronização por parte de quem quer que esteja executando as atividades. Nesse sentido, os POPs significariam a continuidade dos processos, dado que o tempo médio de permanência do estagiário na entidade é de 24 meses. Tais procedimentos também assegurariam que grande parte das dúvidas levantadas na ausência dos professores fossem devidamente esclarecidas.

Os alunos gostam de respostas prontas. Eles vão aprendendo na prática, observando os mais antigos, e não fazem a leitura necessária. Quando algum estagiário me pergunta algo que está acessível no POP, respondo logo: faça a leitura do POP correspondente, que você encontrará a resposta. (Pol, 23 meses)

Além dos procedimentos operacionais, encontram-se no local de trabalho vários avisos, como, por exemplo, o de que não se deve efetuar empréstimos de material a outros laboratórios pertencentes à mesma unidade sem a devida autorização; a ata de reunião com itens a serem providenciados pelos estagiários e a data limite para tal; além de relatórios anexados aos equipamentos de uso diário, para que se registre a pessoa que executou a tarefa e o horário em que esta foi realizada, ou seja, uma espécie de rastreabilidade rústica. Essa forma de controle parece ser aquela mais amplamente documentada pela literatura.

(b) Assim como em outros laboratórios, existem normas de segurança do trabalho que visam evitar a contaminação das amostras e dos estagiários e o risco de acidentes mais graves. Constituem-se algumas exigências, como por exemplo: realizar a assepsia das mãos ao iniciar as atividades; retirar brincos, pulseiras, relógios e acessórios; realizar o controle do meio ambiente através de janelas fechadas e da utilização do arcondicionado; usar a geladeira somente para guardar amostras e meios de cultura; não ingerir alimentos no espaço de trabalho; entrar somente se estiver paramentado com touca e máscara; utilizar calçado hermeticamente fechado e não trabalhar caso esteja com algum machucado que a luva não proteja. 
Existem também, algumas regras de conduta dentro do local, tais como a entrada restrita aos estagiários, professores e funcionários terceirizados responsáveis pela limpeza; o uso dos computadores, do telefone e da impressora somente para assuntos relacionados ao estágio; e vestir-se adequadamente, evitando roupas curtas ou decotadas.

(c) O atendimento aos mais de 100 clientes, pessoas físicas ou jurídicas, cadastrados através da emissão de laudos, também pode ser identificado como uma das manifestações das práticas de controle, embora, sutilmente diferente das duas formas anteriores:

Quando emitimos um boletim acordando a água do poço do sr. José [nome fictício], estamos envolvidos com a saúde dele, da sua família e de seus vizinhos, ou seja, de uma comunidade toda ao redor dele. Nosso trabalho envolve muita responsabilidade e é isso que buscamos exigir dos nossos estagiários. (Pol, 23 meses)

As práticas discursivas acerca da importância das atividades para a vida das pessoas são utilizadas freqüentemente na organização, para justificar o rigor da padronização dos procedimentos materializado nos POPs e do controle sobre os corpos, tanto no que tange a sua utilidade quanto ao seu doutrinamento. A idéia de saúde do público externo traz implícita uma valoração de comportamentos específicos. No conjunto, a idéia e a valoração parecem formar uma equação lógica do tipo "se, então". Em outras palavras, se é importante a saúde do público externo, então, é necessário o controle.

(d) Como o curso dos estagiários ligado à faculdade de farmácia é de período integral, cada participante prepara seu próprio horário de estágio entre os intervalos das aulas. São exigidas 12 horas semanais do estagiário voluntário e 20 horas semanais do estagiário bolsista. Nesse contexto de trabalho quase flexível foram adotadas práticas como a de constar o horário de cada estagiário no quadro de aviso, para que todos possam verificar quem deveria estar presente em determinado dia e horário. A folha de ponto, que representa uma forma de registro de carga horária cumprida para que se possa emitir declarações de estágio, sofreu algumas alterações:

Em reunião com dois estagiários bolsistas, desenvolvemos uma folha de ponto individual. Assim, se o aluno informa em seu horário que virá segunda, terça e quinta, colocamos na tabela somente esses dias e o local para indicar os horários de entrada e saída. No final do dia, temos um estagiário responsável que assina. Se o aluno faltar, veremos que ele não veio. Ainda deixamos uma área de anotações adicionais, caso ele queira vir um outro dia para completar sua carga horária. (Pol, 23 meses)

É interessante notar nessa questão do controle da freqüência, não a flexibilidade disponível, mas, como os próprios alunos são responsáveis por averiguar a presença ou a ausência dos demais. Os alunos bolsistas mais antigos, geralmente, são encarregados de exercer controle sobre os demais que, como eles, participam dessa organização voltada para o aprendizado dos estudantes de farmácia.

(e) A questão das bolsas é importante. Para distribuí-las, a direção analisa indicações recebidas dos que já são bolsistas. Portanto, não são concedidas em função de aspectos socioeconômicos, mas, sim, de demonstrações de "desempenho" na organização.

Os mais antigos vão adquirindo maior experiência e, informalmente, mais responsabilidade; isso, quando são esforçados e se interessam. (Evl, 10 meses) 
O ideal seria oferecer bolsa para todos, mas estagiário novo não tem maturidade para isso. Ele tem que ver se realmente gosta e tem afinidade. Muitas vezes, eles trabalham porque precisam do dinheiro e não porque querem aprender. Não desenvolve. (Eb1, 43 meses)

Como os relatos denotam, os novatos não recebem bolsas, pois a experiência e a afinidade são os critérios que determinam a concessão. Isso sugere uma grande proximidade entre essa organização - em tese, orientada para o aprendizado dos futuros farmacêuticos - e a lógica das empresas, de orientação econômica, onde a ascensão se daria, também em tese, pelo mérito. É interessante notar que como são os mais experientes que recebem as bolsas, também são eles os responsáveis por grande parte das práticas de controle sobre os novatos, ainda que com estes compartilhem a condição de aluno.

Apesar desses procedimentos, os orientadores admitiram que as regras são seguidas parcialmente e que os estagiários não cumprem sua carga horária. Alegam que suas atividades profissionais não lhes permitem presença em período integral e que a divisão de responsabilidades entre os estagiários bolsistas mais antigos não resolve totalmente o problema, pois estes são alunos como os demais. Consideram, portanto, que os alunos são todos iguais.

\section{Controle do laboratório: as táticas do poder}

Nas entrevistas, os estagiários destacaram a importância da experiência adquirida no estágio para se construir um aprendizado prático, que consideram necessário ao profissional graduado em farmácia (i.e., a velha e boa separação entre teoria e prática). Enfatizaram também que, por se tratar de uma organização formada principalmente por alunos, a convivência e a "camaradagem" fazem parte do seu dia-a-dia profissional.

Com relação ao Manual de procedimentos operacionais padrão, elaborado pelo laboratório, os relatos mostraram a existência de ambigüidades quanto à sua aplicação. Alguns acreditam que os POPs constituem uma forma de controle que limita o conhecimento, uma vez que são "receitas de bolo", procedimentos escritos que não proporcionam uma visão geral do processo. Outros defendem a sua aplicabilidade, pois acreditam que "o POP auxilia e padroniza os procedimentos, e só limita aqueles que não querem procurar sobre ele. Isso depende de cada pessoa buscar outra fonte para aumentar seu conhecimento" (Eb1, 43 meses).

Quanto ao atendimento às normas de segurança, os relatos demonstraram que vários procedimentos não são seguidos, haja vista que os estagiários recorrem a várias táticas para driblar as normas exigidas. Por exemplo, refeições são guardadas na geladeira e, nas salas, o meio ambiente não é controlado pelo ar-condicionado, pois as janelas são mantidas abertas. Cabe observar que as táticas usadas para driblar as normas de segurança extrapolam questões de estrutura física.

Estava com uma argola [brinco] enorme. Quando o professor chegou, coloquei ela pra dentro da touca. (Eb3, 17 meses)

Outro dia, à tarde, estava muito quente e trabalhei de sandálias. Quando o estagiário responsável apareceu, escondi meus pés embaixo da mesa. (Ev3, 11 meses)

É interessante observar que essas táticas estão relacionadas com a habilidade do indivíduo de falsear determinadas situações, manobrando objetos que supostamente burlam a "ordem estabelecida", num jogo de esconde/mostra. Tais manobras não se ligam exclusivamente a esses "objetos ilegais", mas também aos "legais". Mesmo objetos como as mesas do laboratório, assim como os pés, servem para uma teatralização, na medida em que representam (e apenas representam) a conformidade com os scripts com que se pretende regular o espaço da organização estudada. 
O fato da sala de estudos e pesquisa ficar mais afastada, mais "no interior" do laboratório, não impede que os estagiários levem visitantes para o local, inclusive, no horário de almoço, contrariando as determinações da organização.

Precisava usar o computador para fazer uma pesquisa e tinha um estagiário fazendo trabalho com mais dois amigos de sala que eu nem conhecia. (Eb2, 17 meses)

Os entrevistados divergem quanto à obrigatoriedade do cumprimento da carga horária semanal. Alguns a relacionam a disciplina e organização, enquanto outros acham que deveria ser menos rígida ou, mesmo, extinta. Nesse aspecto, foram observadas táticas que expressariam "camaradagem”, quando, por exemplo, alguém pede a outro que assine a folha de ponto em seu lugar. Também foi constatado o recurso a táticas individuais, como a de não descontar o horário de almoço ao registrar as horas trabalhadas, anotando um horário em que se esteja em aula, num revezamento entre a sala de aula e o laboratório. É uma forma de se estar lá e não estar, simultaneamente.

Verificamos ainda que a tecnologia informacional não influencia as atividades dos estagiários, na medida em que o emprego de tecnologia mais sofisticada se restringe aos equipamentos de análise. Por outro lado, encontramos uma tática bastante interessante no uso dos computadores, a qual expressa a astúcia humana nos pequenos detalhes do dia-a-dia. Trata-se das visitas a sites proibidos, que não se restringem ao horário de almoço ou quando da ausência de outros estagiários. Ocorrem também na presença de vigilância. Para isso, deixa-se mais de uma "janela" aberta, pois através da minimização é possível substituir rapidamente o site proibido pelo permitido:

Antes, quando queríamos entrar em sites bloqueados, íamos em ferramentas, opções da Internet e clicávamos em um ícone. Quando terminávamos, voltávamos lá e desmarcávamos. Mas esse segredo foi passando para os demais, até que a orientação ficou sabendo e agora isso não funciona mais. (Eb5, 17 meses)

É interessante notar como as táticas são descobertas. Já que não há no laboratório um sistema informacional de acompanhamento de todas as atividades, os alunos conseguem utilizar os instrumentos computacionais para desfrutar de sites não permitidos. A suspeita compartilhada entre alguns dos alunos é a de que essas informações chegam aos professores por meio dos alunos bolsistas, e a estes. pelos que pleiteiam ser.

O acompanhamento individual é feito com maior intensidade no início do estágio pelos próprios estagiários mais antigos, através de treinamentos, da apresentação dos POPs e do esclarecimento de possíveis dúvidas. Estes admitem sua responsabilidade no processo de transmissão de conhecimento aos novos membros, justamente, por se tratar de uma organização ligada a uma instituição de ensino. Obviamente, eles não transferem apenas informações objetivas sobre como realizar o trabalho, mas também as condutas corretas e desejadas nesse espaço.

Depreende-se dos relatos que os indivíduos não se sentem vigiados, controlados ou punidos quando ocorrem falhas ou quando os resultados não são alcançados. No entanto, um dos relatos contraria esse entendimento quando chama a atenção para determinada situação, expressando que, nessa organização formada por alunos, as punições são por eles próprios conduzidas:

Punição não existe, mas quando a pessoa vai fazendo coisas erradas freqüentemente e vemos que ela não se interessa, ela vai ficando mais de lado, deixada pra lá, até que ela mesma desiste de continuar. (Eb1, 43 meses) 
As táticas descritas enfatizam a existência de uma organização formada por estagiários que, além da direção, ou conjuntamente com ela, exercem algum tipo de controle sobre os demais. Entretanto, o interessante nesse último relato é a indicação de que a exclusão cumpre um papel importante no exercício do controle entre os próprios alunos. Em outras palavras, entre os próprios estagiários existe uma pressão social para que haja dedicação às atividades da organização, de forma que aqueles que não demonstram esse tipo de conduta sejam progressivamente "deixados para lá". Com relação a isso, não identificamos a existência de uma tática específica.

Para finalizar a apresentação dos resultados, gostaríamos de indicar aspectos interessantes que nos surpreenderam durante as investigações. Os relatos permitem compreender que, nesse contexto organizacional, há certo clamor, da parte dos próprios controlados, por maior controle:

[...] acontece atrito se eu cobrar alguma coisa de alguém porque sou estagiário igual a eles. O ideal seria que algum técnico pudesse ficar aqui em período integral e cobrar da gente. (Eb1, 43 meses)

[...] não tem uma pessoa com uma ordem maior para fazê-las cumprir (Ev1, 10 meses).

As discussões teóricas empreendidas sobre as idéias de Foucault e Certeau não dão conta desse "desejo de ser controlado". Para tanto, desenvolveremos na próxima seção uma análise da questão com base em referenciais ainda não expostos.

\section{Discussão}

Após a descrição dos resultados, mostra-se importante discutirmos as questões teóricas e empíricas de nossa investigação. Nesse sentido, gostaríamos de nos concentrar em dois pontos: as táticas na organização e a demanda por mais controle.

$\mathrm{Na}$ introdução deste artigo, argumentamos que a polarização entre ciência positiva e estudos críticos não é muito útil para a análise do poder e do controle nas organizações. Se, por um lado, a tradição platônica requer uma questionável regulação, a tradição crítica pretende uma, também questionável, transformação. Ambos são discursos de poder. Ambos também negligenciam o cotidiano das pessoas nas organizações. Nesse sentido, trouxemos Foucault e Certeau para um embate e percebemos que, por mais fortes que sejam as práticas de exercício do poder, não há possibilidade de pôr fim à astúcia humana. Em outras palavras, os corpos não podem ser totalmente docilizados. Isso se destacou quando pudemos nos aprofundar na realidade ora investigada, atentos aos detalhes do dia-a-dia. $\mathrm{O}$ quadro 1 busca sumarizar as práticas e as táticas desenroladas na organização. 


\section{Quadro 1- Síntese das práticas e táticas do poder}

\begin{tabular}{ll}
\hline Práticas de poder & Táticas de poder \\
\hline Padronização dos processos expressa nos POPs. & $\begin{array}{l}\text { Não leitura e execução de procedimentos próprios } \\
\text { para a realização das tarefas. }\end{array}$ \\
\hline $\begin{array}{l}\text { Retirar brincos, pulseiras, relógios e acessórios e } \\
\text { utilizar calçado fechado. }\end{array}$ & $\begin{array}{l}\text { Os acessórios são escondidos sob as roupas, a touca } \\
\text { ou as luvas. Os pés são escondidos sob as mesas } \\
\text { quando se está com algum calçado aberto. }\end{array}$ \\
\hline $\begin{array}{l}\text { Usar a geladeira somente para guardar amostras e } \\
\text { meios de cultura. Manter o ar-condicionado ligado. }\end{array}$ & $\begin{array}{l}\text { São guardadas refeições e lanches na geladeira. As } \\
\text { janelas físicas são abertas e o ar condicionado é } \\
\text { desligado. No uso do computador, deixa-se mais de } \\
\text { uma página da Internet aberta, que é minimizada }\end{array}$ \\
relacionados ao laboratório. & $\begin{array}{l}\text { quando alguém chega. Essa tática é usada no horário } \\
\text { de almoço dos responsáveis. }\end{array}$ \\
\hline $\begin{array}{l}\text { 12 horas de trabalho semanais para estagiário } \\
\text { voluntário e } 20 \text { horas semanais para estagiário } \\
\text { bolsista. }\end{array}$ & $\begin{array}{l}\text { Cumpre-se, em média, 10 e 18 horas, } \\
\text { respectivamente. A saída para o almoço não é } \\
\text { fescontada, pede-se a alguém para assinar e reveza- } \\
\text { Folha de ponto personalizada. }\end{array}$ \\
\hline
\end{tabular}

Fonte: elaborado pelos autores.

Pudemos averiguar em nossa investigação as trampolinagens e os malabarismos dos membros da organização. Foi interessante compreender o jogo em andamento. Não um jogo de estratégias feitas por "pequenos maquiáveis", mas um jogo (sem regras fixas) de esconde/mostra brincos, calçados abertos e "janelas" da Internet; de reinvenção das atividades; de estar/não estar no local de trabalho. Acreditamos que isso altere, num sentido mais amplo, a reificação da organização "total", tão disseminada nos estudos organizacionais.

Apesar da riqueza trazida pela perspectiva aqui adotada, defrontamo-nos, como já foi indicado, com a demanda dos alunos participantes da organização por mais controle sobre as suas atividades. Isso, talvez seja muito mais estranho aos estudos críticos que aos funcionalistas: como podem os sujeitos que supostamente desejam ser tratados como tais, de maneira emancipada, sem distorção nas comunicações, desejarem ser mais controlados? Que fenômeno é esse, tão estranho, mesmo para a idéia de tática?

Quando nos deparamos com esse fenômeno, ficamos intrigados, já que nosso background teórico expressa, grosso modo, "pequenas libertações"; isto é, as táticas são veículos de não-docilidade ante o poder disciplinar. Como podem tais táticas conviver com o desejo de sua própria eliminação por parte dos que a elas recorrem? Procuramos, então, uma explicação para esse paradoxo num autor a que muito raramente se recorre ao discutirmos as organizações.

La Boétie (1997) escreveu sua obra no século XVI, período em que os estados absolutistas consolidavam sua hegemonia paralelamente ao desenvolvimento do Estado-nação. Foi um período que ainda mostrava a força dos reis e a forma tirânica como os governos eram conduzidos. Naquela oportunidade, ele se perguntou sobre o que faria homens e mulheres se submeterem ao jugo impiedoso que deles tira toda a liberdade, conferindo-lhes um caráter de "qualquer coisa", incompatível com a condição humana. Ele analisou o quanto de aberrante há na sujeição das massas ("arraia miúda e embrutecida") ao poder absoluto, na necessidade de obedecer, e indicou o hábito como uma primeira razão para esse tipo de servidão voluntária. O costume levaria as pessoas a "engolir" todas as coisas e a deixarem de sentir o amargor da servidão. 
Não é preciso pegar em armas ou exercitar a violência por outros meios para livrar-se do jugo. Para La Boétie (1997), basta não dar apoio ao tirano. Portanto, se a servidão é concreta, é porque os homens e mulheres apóiam o seu próprio jugo. Algo semelhante levou Arendt (1994) a considerar que o poder não está junto aos "poderosos" e sim aos indivíduos que os sustentam, pois o "poder" não pertence a ninguém concretamente no "poder". Aqueles se utilizam de práticas violentas porque o poder a eles escapa. Em outras palavras, onde há o poder não há a violência. É possível, então, dizer que as formas organizacionais são produtos e produtoras dessas realidades, as quais são sustentadas pelo apoio da maioria que retira ou nega definições heréticas da realidade? Ou existem também representantes que argumentativa e implicitamente "defendem" a continuidade das coisas?

Se possível fosse substituirmos o "tirano" de La Boétie (1997) pela idéia de "organização" - que nos últimos dois séculos se apresentou como uma forma dominante de reprodução da realidade social e de destruição do mundo - e se fizéssemos as mesmas perguntas que o autor, teríamos de reconhecer que homens e mulheres subjugam-se, mesmo usando táticas. Talvez, isso por si já seja uma tática (reconheçamos que as táticas parecem não transformar significantemente coisa alguma) para driblar o modelo dominante de organização. Afinal, construiu-se uma realidade em que a idéia de "liberdade" implica servidão às organizações (os melhores servos ascendem, os indivíduos estudam nas faculdades para se tornarem servos...), à custa da destruição de toda e qualquer alternativa real. Esse último sentido envolve alternativas falsas e seus representantes.

Aqui, estamos nos referindo àqueles que vestem diferentes máscaras, para serem a mesma coisa ("quando mais se muda, mas se é a mesma coisa"); isto é, dizem uma coisa, quando, na verdade, querem dizer outra. Falamos, por exemplo, de Alvesso e Deetz (1996) e de Gaulejac (2006), os quais, entre outros, intentam fazer críticas em seus textos ou autodenominam-se críticos.

Esses autores se dizem críticos porque acusam as empresas (ou a gestão) de não atenderem à necessidade de qualquer ser humano tem de ser tratado como tal, no caso de Gaulejac, e de serem espaços de comunicação distorcida, no de Alvesson e Deetz. Acrescentam que o lucro é intransponível (i.e. que não pode ser superado), que a criatividade humana é imprescindível para as empresas, pois as constroem, que é importante uma ruptura epistemológica (tão somente), um olhar com outros olhos para alcançar $o$ progresso (e isso realmente está escrito!), no caso de Gaulejac, e que o "autoritarismo" - manifestação de comunicação distorcida - repercute negativamente para as pessoas e, claro, para as empresas, no caso de Alvesson e Deetz.

Poder-se-ia argumentar que qualquer discurso pela mudança radical, na realidade, tornou-se anacrônico - seja porque o muro de Berlim caiu, porque a Rússia se vendeu para a sua própria elite, porque a China se tornou a economia que mais cresce no mundo etc. - daí a idéia de que o lucro é inexorável. Apesar desses eventos, chamamos tal "fenômeno" intelectual de "efeito mola"; isto é, um discurso com pretensa vestidura crítica, cujo projeto visa, na verdade, diminuir as diferenças para mantê-las. Ora, como se espera mudar alguma coisa mantendo-a? Na verdade, querem inserir uma "mola" que suavize as coisas, tornando-as mais toleráveis, aceitáveis, digeríveis. Não é por acaso que são criadas consultorias psicanalíticas para empresas, na pretensão de amainar sofrimentos, no caso de Gaulejac (2006), e promovidos colóquios para serem ouvidos, no caso Alvesson e Deetz (1996). Em outras palavras, pretende-se trocar o significado de "liberdade" pelo de "servidão amenizada".

No caso ora investigado, esse estado de coisas é bastante aparente. Apesar das táticas para driblar as normas, os relatos confirmam o desejo de um acompanhamento superior mais integral e rígido, que, segundo os entrevistados, contribuiria para uma melhor qualidade e maior produtividade no estágio. A própria transformação da universidade sob os efeitos da profissionalização, como disse Marcuse (1999), leva seus alunos à luta pelos bilhetes de entrada na fila do estoque de emprego. Certamente, "mais controle" soa-lhes como "maiores chances de ingressar no mercado de trabalho", o que parece ser muito comum em outras formas 
organizacionais de "capacitação" ligadas às universidades, como, por exemplo, as empresas juniores. Em outras palavras, reproduzem nas universidades a lógica do mercado, da empregabilidade, do ensinar a ser servo, em vez da lógica da reflexão crítica e, mesmo, do engajamento político, no sentido da ação no mundo concreto.

Assim, a servidão voluntária de La Boétie (1997) se coaduna, em certo sentido, com o servilismo interessado de Bourdieu (2004). Segundo este, jovens pesquisadores (alunos) são envolvidos simbolicamente pelos "ganhos" financeiros, políticos e de status "oferecidos" por professores-pesquisadores ocupantes de posições prestigiosas (que os transformariam numa "clientela dócil") e "por todo [um] cortejo de citações de complacência e de homenagens acadêmicas" (Ibidem, p.39). Como já havia enfatizado Tragtenberg (1979, $\mathrm{p} 18)$,

o mestre possui um saber inacabado e o aluno, uma ignorância transitória: não há saber absoluto, nem ignorância absoluta. A relação de saber não institui a diferença entre aluno e professor: a separação entre aluno e professor opera-se através de uma relação de poder simbolizada.

Há também outra possibilidade de reflexão por meio da noção de organizational outflanking (MANN apud HARDY; CLEGG, 1996, p. 628), que revela o porquê dos dominados freqüentemente consentirem sua própria dominação. Desse ponto de vista, os membros consentem, de um lado, porque não conhecem o bastante para resistir, e, de outro, por conhecerem demais a futilidade de tal ação. Nesse último caso, transparece a idéia da não-resistência direta pela aceitação das "regras" de sobrevivência do espaço organizacional; isto é, os membros reconhecem o que está em andamento e se sujeitam, para manterem suas condições de vida individuais. Seja como for, o resultado é a serventia.

Sabemos pelo nosso próprio background teórico que os indivíduos não podem ser totalmente docilizados, ainda que, para nós, o paradoxo que constatamos se mantenha. É interessante observar que, embora, no dia-a-dia das organizações, as pessoas desenvolvam suas táticas - numa expressão do exercício de "pequenas liberdades" -, a "forma organizacional dominante" parece ser persistente, num sentido mais amplo. Do modo como indicamos nos resultados da pesquisa, os professores declaram-se conscientes de que as regras não são obedecidas e de que os estagiários não cumprem sua carga horária adequadamente. Isso é bastante curioso e denota conhecimento das táticas usadas. Mas por que não tomam atitudes mais incisivas? A resposta mais pertinente, talvez, seja a de que as táticas não alteram significativamente a "ordem das coisas", de maneira tal que são possíveis "pequenas liberdades" no interior do laboratório de controle.

\section{Considerações finais}

Este artigo teve como objetivo principal analisar as práticas do poder - tipicamente expressas pelos mecanismos de controle das atividades de trabalho - e suas táticas, representadas pelo drible, pelas trampolinagens, num reflexo da astúcia humana. Nosso estudo focou as atividades diárias de alunos num laboratório de análise de alimentos e águas. Para tanto, empreendemos uma abordagem qualitativa de investigação, por meio de entrevistas, de dados produzidos pela própria organização e pela observação nãoparticipante. Gostaríamos de destacar como esse último método é útil para uma investigação da natureza da que aqui foi realizada. Seria particularmente difícil operacionalizar um estudo das táticas, caso estivéssemos distantes da realidade da organização. Embora no caso aqui abordado não nos tenha sido permitido participar efetivamente do trabalho que investigávamos, o fato de estarmos diariamente na organização permitiu visualizar questões que de tão infinitesimais, não poderiam ser apreendidas de outra maneira.

Nossa investigação foi bastante rica de detalhes porque permitiu apreender um "jogo" de esconde/mostra, estar/não estar, que acreditamos representar muito bem o que é o dia-a-dia de trabalho. Revela que, se realmente existe uma racionalidade, ela não reside no cotidiano, pois nos foi permitido o entendimento dos 
"jogos" com o corpo e com os objetos, levando-nos a questionar não apenas a imagem de racionalidade que as organizações tentam construir, mas também a própria eficácia do poder disciplinar no interior dessas organizações.

Há uma questão reflexiva que pode ser levantada a partir da discussão empírica, que serve para uma crítica social a algumas atividades desenvolvidas nas universidades. Muitas organizações vinculadas a uma universidade federal, como a aqui apresentada, freqüentemente, contam com bolsistas e voluntários para o desempenho de suas atividades. É muito comum que essas organizações reúnam alunos de diferentes faculdades. No caso em estudo, o corpo discente é oriundo, basicamente, da própria faculdade. Freqüentemente, também, essas organizações atraem esses estudantes pela oferta de bolsas de estudo e pela perspectiva de prestígio social (entre outros "benefícios"), mas, sobretudo, pela promessa de aquisição de conhecimentos produzidos pelos processos de aprendizado interno almejados pelos futuros profissionais. Contudo, os relatos dos participantes da organização investigada são críticos quanto à condução das atividades ali desenvolvidas, no que diz respeito ao trabalho propriamente dito. Aqui, parece haver um problema de ponderação entre as promessas de aprendizado e as rotinas de execução de um trabalho altamente padronizado. Ora, como essas duas coisas podem se coadunar? Tais organizações parecem envolver seus alunos de uma forma simbólica, escondendo o que realmente fazem sob a vestidura do aprendizado. Isso é uma questão muito importante, inclusive, acreditamos, para as relações entre professores e orientadores nos programas de mestrado e doutorado no Brasil.

Vista de outro ângulo, a abordagem aqui empreendida amplia as possibilidades de estudo do poder e do controle nas organizações. Na medida em que ela permite uma incursão no micromundo vivido, possibilita apreender as relações humanas e objetais no cerne do trabalho diário, isto é, nas práticas diárias nas quais os atores se engajam. A partir dessa abordagem, não é possível considerar os pontos de vista gerencial e crítico, já que as táticas parecem insinuar a ampliação das zonas de controle dos supostamente controlados e, simultaneamente, reproduzir e sofisticar determinados mecanismos de controle.

O estudo das práticas e das táticas de poder permite compreender as organizações como relações de forças sempre tensas, nas quais o núcleo de poder é tomado como difuso e espraiado, terminando por envolver a todos numa dada organização. Mesmo nas relações simbolizadas entre professores e alunos, aqueles são questionados por estes, devido às constantes ausências ao trabalho, configurando de certa forma um exercício de poder, ainda que silencioso. Implícito é: por que existe uma lista de presença para os alunos e não para os professores? Uma questão que fica é saber quando as vozes silenciosas são ouvidas e como isso implica uma (re)configuração das tensas relações.

Por fim, gostaríamos de enfatizar aqui a nossa discussão sobre o paradoxo da servidão, conforme exposto anteriormente. Parece-nos muito estranha a idéia de que os produtores das táticas queiram ser mais controlados; estranha, principalmente, para aqueles pesquisadores preocupados com as mudanças sociais. Seriam aquelas "pequenas liberdades" suficientemente libertárias para os referidos produtores de táticas? Como se pode, por exemplo, discutir emancipação humana nesse quadro? E nossa situação como professores universitários nos cursos de administração? Não são segredo para ninguém as dificuldades enfrentadas quando trazemos para discussão uma definição "herege" da realidade: se ela não serve para aumentar a competitividade, não serve para nada. Se ela não serve para ajudá-los a servir melhor, não faz sentido. Acreditamos que essa questão seja importante e que mereça o empenho dos interessados nessa discussão. Sabemos da força das idéias de La Boétie, principalmente, se a atenção recair sobre o tema da servidão. Nesse sentido, o texto desse autor deve ser visto como um clamor à liberdade que continua atual, mesmo séculos após sua publicação. 


\section{Referências}

ALVESSON, M.; DEETZ, S. Critical theory and postmodernism approaches to organizational studies. In: CLEGG, S. R; HARDY, C.; NORD, W. R. (Org.). Handbook of organization studies. [S.I.]: Sage Publications, 1996, p.191-217.

; WILLMOTT, H. On the idea of emancipation in management and organization studies. Academy of Management Review, v.17, n.3, p.432-464, 1992.

ARENDT, H. Sobre a violência. Rio de Janeiro: Relume-Dumará, 1994.

BARNARD. C. As funções do executivo. São Paulo: Atlas, 1971.

BOÉTIE, E. L. Discurso sobre a servidão voluntária. 2.ed. Lisboa: Edições Antígona, 1997.

BOGDAN, R.; BIKLEN, S. Investigação qualitativa em educação. Porto: Porto Editora, 1994.

BOURDIEU, P. Razões práticas: sobre a teoria da ação. 4.ed. São Paulo: Papirus, 2003. p.224.

Os usos sociais da ciência: por uma sociologia clínica do campo científico. São Paulo: Unesp, 2004.

BRAVERMAN, H. Trabalho e capital monopolista: a degradação do trabalho no século XX. Rio de Janeiro: Zahar Editores, 1974.

CAPPELLE, M. C. A.; BRITO, M. J. Poder disciplinar e gestão de pessoas: um estudo empírico numa organização de desenvolvimento de software. Organização e Sociedade, v.10, n.6, p.19-37, jan./abr. 2003.

CASSIRER, E. O mito do Estado. São Paulo: Códex, 2003.

DE CERTEAU, M. A invenção do cotidiano: artes de fazer. 9.ed. Petrópolis: Vozes, 1994. v.1.

DENZIN, N. K. The research act: a theoretical introduction to sociological methods. Englewood Cliffs, NJ: Prentice-Hall, Inc., 1989.

DURKHEIM, E. O suicídio: estudo de sociologia. São Paulo: Martins Fontes, 2004.

FOUCAULT, M. História da sexualidade I: a vontade de saber. 10.ed. Rio de Janeiro: Graal, 1988.

Vigiar e punir: história da violência nas prisões. 14.ed. Rio de Janeiro: Graal, 1996.

Microfísica do poder. 14.ed. Rio de Janeiro: Graal, 1999.

Microfísica do poder. 19.ed. São Paulo: Graal, 2004.

FREITAG, B.; ROUANET, S. P. Introdução. In: FREITAG, B.; ROUANET, S. P. (Org.). FERNANDES, F. (Coord.). Habermas: sociologia. São Paulo: Ática, 2001.

GAULEJAC, V. Crítica dos fundamentos da ideologia da gestão. In: CHANLAT, J-F; FACHIN, R.; FISCHER, T. (Org.). Análise das organizações: perspectivas latinas. Porto Alegre: Editora da URFGS, 2006. p.413-438.

GIDDENS, A. As conseqüências da modernidade. São Paulo: Unesp, 1991.

. A constituição da sociedade. São Paulo: Martins Fontes, 2003.

HAGUETE, Teresa M. F. Metodologias qualitativas na sociologia. Petrópolis: Vozes, 2003.

HARDY, C., CLEGG, S. R. Some dare call it power. In: CLEGG, S. R; HARDY, C.; NORD, W. R. (Org.). Handbook of organization studies. [S.I.]: Sage Publications, 1996. 
HEGEL, G.W.F. Fenomenologia do espírito. Petrópolis: Vozes, 2000.

HOBBES, T. Leviatã: ou matéria, forma e poder de um estado eclesiástico e civil. João Paulo Monteiro e Maria Beatriz Nizza da Silva (Trad.). São Paulo: Editora Abril, 1974.

MARCH, J. G.; SIMON, H. A. Teoria das organizações. 2.ed. Rio de Janeiro: FGV, 1970.

MARCUSE, H. Razão e revolução. Rio de Janeiro: Saga, 1969.

. A grande recusa hoje. In: LOUREIRO, I. (Org.). Petrópolis: Vozes, 1999.

MARX, K. O capital - crítica da economia política. Livro primeiro. Tradução: Reginaldo Sant'Anna. 11.ed. Rio de Janeiro: Editora Bertrand Brasil - Difel, 1987. v.1.

PAÇO-CUNHA, E. et al. Práticas versus táticas: praxeologia do poder numa organização de tecnologia. In: ENCONTRO NACIONAL DA ANPAD, 30., 2006, Salvador. Anais... Salvador: Anpad, 2006. 1 CD-ROM.

PARSONS, T. Structure and process in modern societies. New York: Free Press, 1960.

ROSA, A. R. Efeito Foucault na análise organizacional. Revista de Administração de Empresas, v.46, n.2, p.120-121, 2006.

SEIDMAN, I. E. Interviewing as qualitative research: a guide for researchers in education and the social sciences. New York: Teachers College, Columbian University, 1991.

SILVERMAN, D. Interpreting qualitative data. London: Sage, 1993.

THOMAS, R.; DAVIES, A. Theorizing the micro-politics of resistance: new public management and managerial identities in UK public services. Organization Studies. v.26, n.5, p.683-706, 2005.

TRAGTENBERG, M. A delinqüência acadêmica: o poder sem saber e o saber sem poder. São Paulo: Rumo, 1979.

WEBER, M. Economia e sociedade. Brasília: UNB, 1999. v.2.

Ensaios de sociologia. 5.ed. Rio de Janeiro: LTC, 2002.

\footnotetext{
${ }^{1}$ Principalmente entre as páginas 64 e 79.

${ }^{2}$ Precisamos ser enfáticos nesse ponto. De forma alguma, estamos propondo uma estruturação ou um construtivismo estruturalista. São bem conhecidas as proposições de Giddens (2003) e de Bourdieu (2003) a esse respeito.
} 